\title{
Risk Factors of Mortality in Acute Lower Respiratory Tract Infections in Children (1 Month to 5 Years)
}

\author{
Tiwari V. ${ }^{1}$, Purohit A. ${ }^{2}$, Gedam DS ${ }^{3}$ \\ ${ }^{1}$ Dr. Varsha Tiwari, Assistant Professor, Department of Paediatrics, Sri Shankaracharya Institute of Medical Sciences, \\ Bhilai (CG) India, ${ }^{2}$ Dr. Ashish Purohit, DM Nephrology Resident, Department of Nephrology, Sri Aurobindo Medical \\ College and Postgraduate Institute, Indore (MP) India, ${ }^{3}$ Dr. D Sharad Gedam, Associate Professor, Department of \\ Paediatrics, Atal Bihari Vajpai Government Medical College, Vidisha, MP, India.
}

Corresponding Author: Dr. D Sharad Gedam, Associate Professor, Department of Paediatrics, Atal Bihari Vajpai Government Medical College, Vidisha, MP, India. E-mail: sharad.gedam@gmail.com

\begin{abstract}
Introduction: ARI has been estimated to be the single largest cause of death in young children. This study will be used to evaluate factors that may predict mortality due to ALRTI in children, thus helping to identify those at risk, so that timely therapeutic measures may be instituted. Material and Methods: A prospective case control study on 200 children with acute lower respiratory tract infections in the age group of 1 month to 5 years of age, conducted during the period august 2010 to October 2011 at Ekta institute of child health, Raipur, C.G. Detailed history, clinical examination, radiological and biochemical tests were done. Case fatality rate was calculated using formula- Total number of deaths due to a particular disease / Total number of cases due to the same disease $\times 100$ Chi square test was applied and $\mathrm{p}$ value calculated. Results: Cases were those who died during study \& controls were those who were discharged. There were 182 controls and 18 cases, the risk factors which were evaluated are 1-2 months age, male child, class V socioeconomic status, grade IV malnutrition, very severe pneumonia, afebrile, hyponatremic and hypoxemic patients. Conclusion: In children with an acute lower respiratory tract infection, simple physical signs that require minimal expertise to recognise can be used to determine oxygen therapy and to aid in screening for referral. The association between hypoxemia and death highlights the need for early recognition of the condition and the potential benefit of treatment.
\end{abstract}

Keywords: Acute lower respiratory tract infections, Case fatality rate, Risk factors.

\section{Introduction}

Acute lower respiratory tract infection are being increasingly recognised as a major cause of mortality and one of the common cause of morbidity in children below 5 years of age [1].

Every year 3.9 million deaths occur worldwide. An estimated $29 \%$ of all deaths in children younger than 5 years worldwide occur due to acute lower respiratory tract infection. India, Bangladesh, Indonesia, and Nepal contribute to $40 \%$ of the global ARI mortality. Of $\sim 158$ million episodes of pneumonia per year, 154 million occurs in developing countries [2]. Acute lower respiratory tract infection is responsible for $19 \%$ of all deaths in children below 5 years and $82 \%$ of all disabilities and premature mortality as measured by disability adjusted life years (DALY)[3].

Manuscript received: $10^{\text {th }}$ April 2019

Reviewed: $20^{\text {th }}$ April 2019

Author Corrected: $25^{\text {th }}$ April 2019

Accepted for Publication: $28^{\text {th }}$ April 2019
In India during 2009, about 26.5 million cases of ARI and 7.56 lakh cases of pneumonia. Pneumonia was responsible for about $20 \%$ of all under five year death in India [4]. Lack of breast-feeding, upper respiratory infection in mother, upper respiratory infection in siblings, severe malnutrition, cooking fuel other than liquid petroleum gas, inappropriate immunization for age and history of LRTI in the family were the significant risk factors associated with ALRTI [5].

For doctors and health workers at all levels of health care, it is essential to be aware of the host and clinical factors that influence the outcome of children with acute respiratory tract infection (ALRI).

This study was carried out to evaluate factors that may predict mortality due to ALRI in children, thus helping to identify those at risk, so that timely and appropriate therapeutic measures may be instituted. 


\section{Material and Methods}

Design- It is a prospective case control study of acute lower respiratory tract infections in under five children conducted at Ekta institute of child health, Raipur, C.G.

Source of Data- Children admitted with clinical diagnosis of ALRTI as per WHO criteria form the subjects for the study.

Period of Study- August 2010-July 2011

Inclusion Criteria: Children between 1 month to 5 yrs of age admitted with symptoms suggestive of lower respiratory tract infections. Symptoms less than 30 days duration \& clinical or radiological features consistent with acute LTB, acute laryngitis, bronchiolitis \& bronchopneumonia etc.

Exclusion Criteria: Those who, following admission and their subsequent stay, were diagnosed with other concomitant illnesses like tuberculosis, Asthma, poisoning, and major congenital anomalies of heart and other systems, LAMA, ABSCONDED.

Methods of collection of data- A case of ALRTI is defined as per ARI control programme "presence of cough with fast breathing of more than $60 / \mathrm{min}$ in less than 2 month of age, more than 50/min in 2 month to 12 months of age and more than 40/min in 12 month to 5 year of age, the duration of illness being less than 30 days". The presence of lower chest wall indrawing was taken as evidence of severe pneumonia
Those children who died during the course of their hospitalization served as the cases while those discharged, after improvement or complete recovery were taken as controls. The clinical evaluations of the subjects were recorded on a pretested proforma.

A complete general physical and systemic examination of each patient, including anthopometery (height, weight and mid arm circumference) was carried out.

A total of 209 children were enrolled in the study, of which 9 were subsequently excluded. Of these 9 children, 4 left against medical advice (LAMA), 3 were proven to have illness of tubercular etiology and another 2 had acute exacerbation of bronchial asthma. Of the remaining 200 children, 182 were discharged upon recovery or improvement while 18 died during the course of their hospitalization. Thus 18 cases and 182 controls were available for final analysis.

Statistical analysis- Analysis was carried out on a computer using the programmed statistical package for social sciences (SPSS for window version 6.0).

To find out the risk factors significantly associated with mortality in LRTI, all variables were first evaluated. Case fatality rate was calculated using formula- Total number of deaths due to a particular disease / Total number of cases due to the same disease $\times 100 \mathrm{Chi}$ square test was applied and $p$ value calculated.

\section{Results}

The study material comprised of 200 children with ALRI, between the age of 1 months to five years. Of these 18 died (cases) and 182 were discharged (controls), after they improved. The case fatality rate in this study was $9.0 \%$.

The subjects were divided into three age groups i.e. $<2$ months, $02-12$ months and 12-60 months. There were 29 children in $<2$ months group, 82 children in 02-12 months group and 89 children in 12-60 months age group.

Table-1: Distribution of Subjects According to Age.

\begin{tabular}{|c|c|c|c|}
\hline \multirow{2}{*}{ Age Group } & \multicolumn{3}{|c|}{$\mathrm{N}=\mathbf{2 0 0}$} \\
\hline & Alive & Dead & CFR \\
\hline $\begin{array}{l}\text { I. }<02 \text { Months }) \\
\qquad(\mathrm{N}=29)\end{array}$ & 24 & 05 & $14.28 \%$ \\
\hline $\begin{array}{l}\text { II. } 02-12 \text { months } \\
\qquad(\mathrm{N}=82)\end{array}$ & 72 & 10 & $12.19 \%$ \\
\hline $\begin{array}{l}\text { III. } 12-60 \text { months } \\
\qquad(\mathrm{N}=89)\end{array}$ & 86 & 03 & $4.44 \%$ \\
\hline
\end{tabular}

$\chi 2(\mathrm{df}=2)=6.87, \mathrm{p}=0.03$ 


\section{Original Research Article}

There were a decline in the mortality rate due to ALRI as age increases and the decline in mortality is statistically significant. This fact is verified by obtained $\chi^{2}=6.87$, which has a statistical significance of .01 level. CFR's for $<02$ months, $02-12$ months and 12-60 months are $14.28 \%, 12.19 \%$ and $4.44 \%$ respectively also showing the same result.

Table-2: Distribution of Subjects According to Age and Sex.

\begin{tabular}{|c|c|c|c|c|}
\hline \multirow{2}{*}{\begin{tabular}{c} 
Age Group \\
\cline { 2 - 5 }
\end{tabular}} & \multicolumn{2}{|c|}{ Male (N=119) } & \multicolumn{2}{c|}{ Female (N=81) } \\
\hline \begin{tabular}{c} 
I. $\begin{array}{c}<02 \text { Months } \\
(\mathrm{N}=29)\end{array}$ \\
\cline { 2 - 5 }
\end{tabular} & 10 & 03 & 14 & 02 \\
\hline $\begin{array}{c}\text { II. 02-12 months } \\
(\mathrm{N}=82)\end{array}$ & 50 & 06 & 22 & 04 \\
\hline $\begin{array}{c}\text { III. 12-60 months } \\
(\mathrm{N}=89)\end{array}$ & 48 & 02 & 38 & 01 \\
\hline CFR & \multicolumn{2}{|c|}{$\mathbf{9 . 2 4 \%}$} & & $\mathbf{8 . 6 4 \%}$ \\
\hline
\end{tabular}

In our study group there were more boys than girls $(\chi 2=7.22, \mathrm{p}=0.01)$. Male to female ratio was $1.5: 1$. There were more deaths among males than females but the difference is statistically insignificant $(\chi 2=2, \mathrm{p}=0.15)$. The CFR was $9.24 \%$ (11 deaths in 120 males) in males as compared to $8.64 \%$ in females (07 deaths in 80 females).

Table-3: Diagnosis by WHO Criteria and Mortality.

\begin{tabular}{|c|c|c|c|}
\hline \multirow{2}{*}{ Diagnosis } & \multicolumn{2}{|c|}{$\mathbf{N = 2 0 0}$} & \multirow{2}{*}{ CFR (\%) } \\
\cline { 2 - 4 } & Alive (N=182) & Dead (N=18) & - \\
\hline No pneumonia & 07 & 00 & - \\
\hline Pneumonia & 20 & 00 & 6.66 \\
\hline Severe Pneumonia & 112 & 08 & 25 \\
\hline Very Severe Pneumonia & 30 & 10 & - \\
\hline Wheezing Group & 10 & 00 & - \\
\hline Severe croup & 03 & 00 & \\
\hline
\end{tabular}

$(\chi 2(\mathrm{df}=5)=17.25, \mathrm{p}=0.004)$

The case fatality rate is higher in very severe pneumonia category $(\mathrm{p}<.01)$ as compared to other categories i.e. no pneumonia, pneumonia, severe pneumonia, wheezing and severe croup respectively. This is evident from CFR which indicates mortality occurs in only severe and very severe pneumonia patients.

Table-4: Socio Economic Status.

\begin{tabular}{|c|c|c|c|}
\hline \multirow{2}{*}{ SES $\downarrow$} & \multicolumn{2}{|c|}{$\mathbf{N = 2 0 0}$} & \multirow{2}{*}{ CFR (\%) } \\
\cline { 2 - 4 } & Alive (N=182) & Dead (N=18) & - \\
\hline $\begin{array}{c}\text { Class I } \\
(\mathrm{N}=4)\end{array}$ & 04 & 00 & 5.55 \\
\hline $\begin{array}{c}\text { Class II } \\
(\mathrm{N}=18)\end{array}$ & 17 & 01 & 5.63 \\
\hline $\begin{array}{c}\text { Class III } \\
(\mathrm{N}=71)\end{array}$ & 67 & 4 & 10.98 \\
\hline $\begin{array}{c}\text { Class IV } \\
(\mathrm{N}=91)\end{array}$ & 81 & 10 & 18.75 \\
\hline $\begin{array}{c}\text { Class V } \\
(\mathrm{N}=16)\end{array}$ & 13 & 03 & \multirow{2}{*}{} \\
\hline
\end{tabular}

$\chi 2(\mathrm{df}=4)=11.98, \mathrm{p}=0.01$ 


\section{Original Research Article}

The higher case fatality rate was observed in Socio Economic Class $\mathrm{V}(\mathrm{p}<.01)$ which is statistically significant. It reveals that mortality due to ALRI was seen in following order among various SES groups: Class V, IV, III, II and no mortality in class I.

Table-5: According to Nutritional Status.

\begin{tabular}{|c|c|c|c|}
\hline \multirow{2}{*}{ IAP Grade $\downarrow$} & N=200 & \multirow{2}{*}{ CFR } \\
\cline { 2 - 4 } & Alive (N=182) & Dead (N=18) & - \\
\hline Normal $(\mathrm{N}=10)$ & 10 & 0 & 4.16 \\
\hline Grade I (N=24) & 23 & 1 & 1.61 \\
\hline Grade II (N=62) & 61 & 09 & 11.53 \\
\hline Grade III (N=78) & 69 & 7 & 26.92 \\
\hline Grade IV $(\mathrm{N}=26)$ & 19 & 1 & \\
\hline
\end{tabular}

$\chi 2(\mathrm{df}=4)=16.61, \mathrm{p}=0.002$

Highest case fatality rate i.e. $26.92 \%$ was observed in patients belonging to IAP grade V malnutrition followed by Grade III (11.53\%), Grade I (4.16\%) and lastly Grade II (1.61\%). The difference in case fatality rate is statistically significant at .01 level.

Table-6: SPO2 at Room Air.

\begin{tabular}{|c|c|c|c|c|}
\hline & \multicolumn{2}{|c|}{$\mathbf{N}=\mathbf{2 0 0}$} & \multirow{2}{*}{ CFR } & \multirow{2}{*}{$\chi^{2}$} \\
\hline & Alive & Dead & & \\
\hline Age $<2$ months & & & & \\
\hline$<92 \%$ & 6 & 04 & $40 \%$ & 5.54 \\
\hline$>92 \%$ & 18 & 01 & $5.26 \%$ & $\mathrm{p}=0.01$ \\
\hline Age $02-12$ months & & & & \\
\hline$<92 \%$ & 68 & 09 & $11.68 \%$ & 0.30 \\
\hline$>92 \%$ & 04 & 01 & $20 \%$ & $\mathrm{p}=0.58$ \\
\hline Age $12-60$ months & & & & \\
\hline$<92 \%$ & 78 & 02 & $2.50 \%$ & 1.84 \\
\hline$>92 \%$ & 08 & 01 & $11.11 \%$ & $\mathrm{P}=0.17$ \\
\hline
\end{tabular}

Highest case fatality rate is found in $<2$ months age with $\mathrm{SpO}_{2}<92 \%$. The result is statistically significant at .05 level $(\chi 2=5.54)$.

Table-7: Laboratory Testing.

\begin{tabular}{|c|c|c|c|c|c|c|}
\hline \multirow{3}{*}{ Variables $\downarrow$} & \multicolumn{4}{|c|}{$\mathrm{N}=\mathbf{2 0 0}$} & \multirow{3}{*}{ 't } & \multirow{3}{*}{ p value } \\
\hline & \multicolumn{2}{|c|}{ Alive $(\mathrm{N}=182)$} & \multicolumn{2}{|c|}{ Dead $(N=18)$} & & \\
\hline & Mean & S.D. & Mean & S.D. & & \\
\hline Sodium & 139.23 & 5.33 & 130.00 & 6.23 & 8.26 & .01 \\
\hline Potassium & 4.1 & 1.12 & 4.3 & 0.86 & 0.35 & 0.78 \\
\hline
\end{tabular}

The mean sodium is significantly lower in those who died of ALRI as compared to the patients who survived. This finding has statistical weightage at .01 level $(\mathrm{t}=8.26, \mathrm{p}<.01)$.

Table-8: Radiological Features.

\begin{tabular}{|l|c|c|c|}
\hline \multirow{2}{*}{ Age Group $\downarrow$} & \multicolumn{2}{|c|}{$\mathbf{N = 2 0 0}$} & \multirow{2}{*}{ CFR } \\
\cline { 2 - 4 } & Alive $(\mathbf{N}=\mathbf{1 8 2})$ & Dead $(\mathbf{N}=18)$ & 10.77 \\
\hline Opacity present $(\mathrm{N}=167)$ & 149 & 18 & - \\
\hline Opacity not present $(\mathrm{N}=33)$ & 33 & 00 & \multirow{2}{*}{} \\
\hline
\end{tabular}




\section{Original Research Article}

Case fatality rate is $10.77 \%$ in patients who showed opacity in chest $\mathrm{x}$-ray while there was no mortality in patients who did not show opacity in chest $\mathrm{x}$-ray. The resultant chi square is not significant due to Yates correction because CFR can not be ascertained in patients who did not show opacity.

Table-9: Response to Treatment Assessed by Normalization of SPO2 within 48 hrs. of Treatment.

\begin{tabular}{|c|c|c|c|c|}
\hline & \multicolumn{2}{|c|}{$N=167$} & \multirow{2}{*}{ CFR } & \multirow{2}{*}{$\chi^{2}$} \\
\hline & Alive & Dead & & \\
\hline Response to Treatment $(\mathrm{N}=103)$ & 103 & 0 & - & \multirow{2}{*}{$\begin{array}{c}23.73 \\
\mathrm{p}=0.000\end{array}$} \\
\hline No response to Treatment $(\mathrm{N}=64)$ & 49 & 15 & $23.43 \%$ & \\
\hline
\end{tabular}

As expected, highest CFR (23.43\%) was observed in a group of patients who did not respond to treatment. The reported $\chi 2=23.73$ which is statistically significant at .01 proves the above statement scientifically.

\section{Discussion}

Acute respiratory tract infection (ARI) has been estimated to be single largest cause of death in young children in developing countries. Most of the ARI deaths are due to acute lower respiratory tract infection (ALRI), particularly pneumonia.

Therefore, reduction in ALRI mortality is an important issue, particularly so in developing countries.

It is equally important to find out the factors that determine the outcome in ARI. Various studies have been carried out to evaluate the risk factors associated with ARI mortality. However, in many of these studies, the investigators have worked on a particular set of factors. Either host factors have been evaluated $[5,6,7]$ or clinical factors (which are reflection of disease severity) have been studied[8,9]. Only a few of these studies have addressed the issue in totality $[10,11]$.

Though most of the studies have been prospective cohort studies, a few have been retrospective case control studies. The study by Victora et al [5], which had comprehensively evaluated the host factors, was a retrospective case study, as was the study by Deivanayagam et al [10]. Similarly studyby Vineet sehgal et al [12] was prospective case control study.

Our study shows that, CFR in patients less than 2 months is $14.28 \%$, in $2-12$ months is $12.19 \%$ and in 12 60 months is $4.44 \%$.

There is a steady decline in CFR as the age increases and the decline is statistically significant (chi square6.87, P-0.03)

Vineet et al [5], andWeissenbacher et al [13] had found the CFR among subjects less than 1 year to be significantly higher compared to higher age groups.
Deivanayagam et al[10] and Nathoo et al[14] had found age under 6 month Johnson et al[15] interestingly, reported higher mortality in children above 12 months of age $s$ to be significant.

There was a preponderance of boys in the study group, male to female ratio being 1.5:1 and there were more deaths in males than female, CFR being $9.24 \%$ in males compared to $8.64 \%$ in females, but the difference is statistically insignificant $(\chi 2=2, p=0.15)$. Others too found greater proportion of males $[5,12,16,17]$, in their studies.

Our study shows that, when classified according to WHO criteria, out of the 200 subjects with ALRI, 7 were labeled as "No pneumonia", 20 had pneumonia, 120 had severe pneumonia, 40 had very severe pneumonia, 10 had group of diseases presenting with wheezing and 03 had severe croup. Out of these 18 babies died, 08 from severe pneumonia group (CFR$6.66 \%$ ) and 10 from very severe pneumonia group (CFR-25\%). There was no mortality in other groups. The mortality was statistically significant in very severe pneumonia group (chi-square-17.25\%, P-0.004)

Vineet et al [12] found $90.5 \%$ had pneumonia, $9 \%$ had Bronchiolitis, $0.5 \%$ had acute LTB, out of which highest CFR was found in very severe pneumonia, least in pneumonia and wheezing group and one child with severe croup died. This is similar to data in our study.

In two hospital based prospective studies from Papua New Guinea, Shann et al[18] and Spooner et al[19] assessed the clinical signs that predict mortality in children with pneumonia and found that moderate to severe pneumonia had statistically significant impact on mortality of children. However, instead of studying all cases of ALRTI, Shann et al [18] included children only 


\section{Original Research Article}

with severe pneumonia and Spooner et al [19] included children with an admitting diagnosis of moderate or severe pneumonia. Risk factors for severe disease and predictors of mortality were analysed by means of chisquare test, common odds ratio and Mantel-Haenzel method by Spooner et al [19] while Shann et al [18] carried out analysis by chi-square test only.

Socioeconomic status was evaluated on the basis of per capita per month income according to modified Prasad's classification. In our study Table-4 shows that the highest CFR was observed in class V (CFR$18.75 \%$ ) followed by IV (CFR-10.98\%), III (CFR$5.63 \%)$, II (5.55\%) and no mortality in class I. Results obtained were statistically significant $(\chi 2(\mathrm{df}=4)=$ 11.98, $\mathrm{p}=0.01$ ).

Victora et al [5] and Vineet et al [12] had reported significant association between family income and risk of death. Syed Ibrahim et al [16] found similarly significant result i.e. CFR increases as the income decreases.

In our study nutritional status was classified according to IAP classification of malnutrition. As shown in Table-5 Out of 200 subjects, 10 were well nourished, 23 had grade I malnutrition, 61 had grade II, 69 had grade III, and 19 had grade IV malnutrition. Among them, highest case fatality was observed in grade IV malnutrition (CFR-26.92\%) followed by grade III (CFR-11.53\%), grade I (CFR- 4.16\%), grade II (CFR$1.61 \%$ ) and no death was found in well nourished subjects. Results obtained were statistically significant $(\chi 2(\mathrm{df}=4)-16.61, \mathrm{p}-0.002)$. Immuno deficiency and impairment of host responses in malnourished children predisposes them to severe infection and complication of ALRI and consequently higher mortality ${ }^{92}$. Some how in our study CFR was less in grade II than I.

Weissenbacher et al [13], Spooner et al [19], Nathoo et al [14], Shann et al [18] and Deivanayagam et al[10] have all in their respective studies confirmed that malnutrition is a significant risk factor for mortality in children due to ALRI.

Weissenbacher et al [13] on comparing undernourished and well nourished children with ALRTI observed a case fatality rate of $7.6 \%$ and $2.3 \%$ respectively, with a relative risk of 3.3 in the former. Deivanayagam et al[10] showed in their case control study that children with grade III and IV malnutrition were at greater risk of dying as compared to normal children or children with grade I or II malnutrition, adjusted odds ratio for death in the former being 5.8 .
Tupasi et al [20] Falade AG et al [21], Nathon et al [22] and Dharmage et al [23] in their respective studies documented significance of malnutrition as a risk factor of mortality from ALRTI.

Our study shows that, highest CFR (33.66\%) was observed in $<2$ months afebrile patients and lowest CFR $(2.46 \%)$ in $12-60$ months febrile patients, this difference were statistically significant. ( $<2$ months-chisquare-4.54 and P-0.03, 2-12months chi-square -5.86 and P-0.01, 12-60 months-chisquare -2.24 and $\mathrm{P}-0.30$ ).

Shann et al [18] and Spooner et al had [19] reported absence of fever as a predictor of mortality but it lost its significance because of sample size.

Vineet et al [12] found, result which was statistically insignificant.

Our study shows that, mortality was highest in patients 1-2 months age group with $\mathrm{SpO}_{2}<92 \%(\mathrm{CFR}-40 \%)$ and lowest in 12- 60 months of age with $\mathrm{SpO}_{2}<92 \%$ (CFR$2.5 \%$ ). The differences were statistically significant in $<2$ months age group(chi-square 5.54, p=0.01). No significant difference has been observed in age 02-12 months and 12-60 months between patients with $\mathrm{SpO}_{2}$ values $<92 \%$ and $>92 \%$ respectively. The reported chi square in table no. 10 statistically confirms these findings.

The importance of $\mathrm{SpO}_{2}$ monitoring has been proven by various studies. Other studies like prospective cohort study done by Usen S et al [24] found hypoxemia as a significant predictor of mortality in ALRI. Seventeen published studies ${ }^{152}$ were found, that included 4,021 children under 5 years with acute respiratory infections (ARI) and reported the prevalence of hypoxemia. Three papers reported an association between hypoxemia and death, with relative risks varying between 1.4 and 4.6.

Sodium and potassium level of each patient was investigated to assess electrolyte imbalance. The mean sodium in controls was 139.23 while it was 130 in cases as shown in Table-13. The difference in mean sodium among the two groups was statistically significant $(\mathrm{P}$ value-0.01). The mean potassium level among controls was 4.1 and among cases was 4.3.This shows that the difference in potassium level was statistically not significant.

We could not find any study comparing mortality risk in association with electrolytes in ALRTI. Dreyfess D et $\mathrm{al}[25]$ found that there is latent vasopressin dependent impairment of renal water excretion in acute 
pneumonia. Singhi S et al [26] in their study in India showed that out of 264 children admitted to hospital with pneumonia $27 \%$ showed hyponatremia at admission. In $68 \%$ of these subjects, the hyponatremia was secondary to inappropriate ADH secretion.

In our study, Out of 167 subjects, 122 had localised opacity, among which there were no deaths, 45 had diffuse opacity, among which 18 subjects died (CFR$40 \%$ ). The difference in mortality was statistically significant (chi-square-50.61, P-0.000). Vineet et al [12] and Shann et al [18] also found severe chest radiograph changes to be another predictor of mortality. However criteria for labelling severe changes were not detailed.

Acute lower respiratory tract (ALRT) infections cause considerable child morbidity and mortality in developing countries. Oxygen therapy can improve the outcome of children with moderate or severe ALRT infections and, in those with hypoxemia, the severity of hypoxia correlates with outcome.

However, since oxygen is not always available in resource-poor countries, rational guidelines must be followed for the use of oxygen and the referral of patients to specialist hospitals.

\section{Conclusion}

Apart from what have been studied before, we found electrolyte imbalance and responsiveness to treatment with regards to normalisation of spo 2 at 48 hours as significant predictor of mortality in children with ALRI.

Therefore we suggest use of spo2 monitoring in children with ALRI even in the peripheries so that early recognition of hypoxemia and timely management or referral can be done and thus we can decrease mortality due to ALRI.

Funding: Nil, Conflict of interest: None initiated, Perission from IRB: Yes

\section{References}

1. Gareene M, ponsman C, Campbell H. The magnitude of mortality from acute lower respiratory tract infection in children below 5 years in developing countries. World Health State Q. 1992;45:180-189. https://www. researchgate.net

2. Kliegman RM, Marcdante KJ, Jenson $\mathrm{HJ}$, et al: Nelson essentials of pediatrics, ed 5, Philadelphia, 2006, Elsevier, p 504, Nelson text book of paediatrics, $19^{\text {th }}$ edition, 2011, chapter392, 5319.
3. Govt. of India( 2010),National health profile 2009, DGHS, Ministry of health and family welfare, New Delhi, park text book of preventive and social medicine $21^{\text {th }}$ edition 2011; chapter-5,156-157.

4. Broor S, Pandey RM Risk factors for severe acute lower respiratory tract infection in under-five children. Indian Pediatr. 2001 Dec;38(12):1361-9.

5. Victora CG, Smith PG, Barros FC, et al. Risk factors for deaths due to respiratory infections among Brazilian infants. Int J Epidemiol. 1989 Dec;18(4):918-25.

6. Bokade CM, Madhura AD, Bagul AS, et al. Predictors of mortality in children due to severe and very severe pneumonia. Niger Med J. 2015 Jul-Aug; 56 (4) : 287-91. doi: 10.4103/0300-1652.165038.

7. Champatiray J, SatapathyJ. Clinico-Aetiological Study of Severe and Very Severe Pneumonia in Two Months to Five Years Children in a Tertiary Health Care Centre in Odisha, India. J Clin Diagn Res. 2017 Sep; 11 (9): SC06-SC10. doi: 10.7860/JCDR/2017/ 26027. 10595. Epub 2017 Sep 1.

8.Dean P, Florin TA Factors Associated With Pneumonia Severity in Children: A Systematic Review.J Pediatric Infect Dis Soc. 2018 Dec 3; 7 (4): 323-334.

9. Brown SM, Dean NC. Defining and predicting severe community-acquired pneumonia. CurrOpin Infect Dis. 2010 Apr; 23 (2): 158-64. doi: 10.1097/QCO. 0b013e 3283368333.

10. Deivanayagam N, Nedunchelian K, Ramasamy S, et al. Risk factors for fatal pneumonia: a case control study. Indian Pediatr. 1992 Dec;29(12):1529-32.

11. Lupisan SP, Ruutu P, Predictors of death from severe pneumonia among children 2-59 months old hospitalized in Bohol, Philippines: implications for referral criteria at a first-level health facility.Trop Med Int Health. 2007 Aug;12(8):962-71.

12. Sehgal V, Sethi GR, Sachdev HP, Predictors of mortality in subjects hospitalized with acute lower respiratory tract infections. Indian Pediatr. 1997 Mar;34 (3): 213-9.

13.Weissenbacher $M$, Carballal G, Avila $M$ et al. Etiology and clinical evaluation of acute lower respiratory tract infection in young Argentinian children :An overview. Rev infect Dis 1990; 12 : S889-90. 


\section{Original Research Article}

14. Nathoo KJ, Nkrumah FK, Ndlovu D et al. Acute lower respiratory tract infection in hospitalized children in Zimbabwe. Ann Trop pediatr 1993; 13:253-61.

15. Johnson WB, Aderele WI, Gbadero DA. Host factors and acute lower respiratory infections in preschool children. J Trop Pediatr. 1992 Jun;38(3):132-6. doi: 10.1093/tropej/38.3.132.

16. Syed Ibrahim et.al. Study of modifiable risk factors for acute lower respiratory tract infection in under five children, Rajiv Gandhi institute of health sciences.2009

17. Chisti MJ, Tebruegge M, La Vincente $\mathrm{S}$, et al. Pneumonia in severely malnourished children in developing countries - mortality risk, aetiology and validity of WHO clinical signs: a systematic review. Trop Med Int Health. 2009 Oct;14(10):1173-89. doi: 10. $1111 /$ j. 1365-3156.2009.02364.x.

18.Shann F, Barker J, Poore P. Clinical signs that predict death in children with severe pneumonia. Pediatr Infect Dis J 1989;8:852-55.

19. Spooner V, Barker J, Tulloch $\mathrm{S}$ et al. clinical signs $\&$ risk factors associated with pneumonia in children admitted to Goraka hospital, Papua New Guinea. J Trop pediatr $1989 ; 35: 295-300$.

20. Tupasi TE, Mangubat NV, Sunico MES et al. Malnutrition and acute respiratory tract infection in Filipino children. Rev infect Dis 1990;12:S1041-54.
21. Falade AG, Tschappeler H, Greenwood BM; Mulholland EK, Malnutrition affects the ability of simple clinical signs to predict pneumonia in young Gambian children. Bull world health organ.1995; 73: 299-304.

22. Nathan KJ, Nkrumah Fk, Ndlovu M, Pirie DJ, Kowoh. Acute lower respiratory tract infection in hospitalized children in Zimbabwe. Ann Trop Paediatr 1993;13:253-61.

23. Dharmage SC, Rajapaksa LC, Fernando DN. Risk factors of acute lower respiratory tract infections in children under five years of age. South east Asian J Trop Med Public Health 1996;27:107-10.

24. Usen S, Weber M, Mulholland K, et al. Clinical predictors of hypoxaemia in Gambian children with acute lower respiratory tract infection: prospective cohort study. BMJ. 1999 Jan 9; 318 (7176): 86-91.

25. Dreyfuss D, Leviel F, Paillard M, et al. Acute infectious pneumonia is accompanied by a latent vasopressin-dependent impairment of renal water excretion. Am Rev Respir Dis. 1988 Sep;138(3):583-9. DOI:10.1164/ajrccm/138.3.583

26.Singhi S, Dhawan A. Frequency and significance of electrolyte abnormalities in pneumonia. Indian Pediatr. 1992 Jun; 29(6):735-40.

\section{How to cite this article?}

Tiwari V, Purohit A, Gedam DS. Risk Factors of Mortality in Acute Lower Respiratory Tract Infections in Children (1 Month to 5 Years). Int J Pediatr Res. 2019;6(04):150-157.doi:10.17511/ijpr.2019.i04.01 